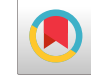

\title{
Association Between Personality Types and Temperament(Mizaj) Based on Persian Medicine
}

\author{
Mohammad Mahdi Parvizi ${ }^{1,{ }^{*}}$, Majid Nimrouzi ${ }^{2,{ }^{* *}}$, Mehdi Pasalar ${ }^{3}$, Alireza Salehi $^{3}$, Mahdie $^{2}$ \\ Hajimonfarednejad ${ }^{3}$, Fatemeh Amini $^{3}$, Reza Mousavi Shirazi ${ }^{4}$ and Pyruz Rezaie ${ }^{5}$ \\ ${ }^{1}$ Molecular Dermatology Research Center, Shiraz University of Medical Sciences, Shiraz, Iran \\ ${ }^{2}$ Department of Traditional Persian Medicine, School of Medicine, Shiraz University of Medical Sciences, Shiraz, Iran \\ ${ }^{3}$ Research Center for Traditional Medicine and History of Medicine, Shiraz University of Medical Sciences, Shiraz, Iran \\ ${ }^{4}$ Shiraz Medical School, Shiraz University of Medical Sciences, Shiraz, Iran \\ ${ }^{5}$ Research Center for Psychiatry and Behavioural Sciences, Department of Psychiatry, Shiraz University of Medical Sciences, Shiraz, Iran \\ "Corresponding author: Molecular Dermatology Research Center, Shiraz University of Medical Sciences, Shiraz, Iran. Tel: +98-7132125592, Email: mmparvizi@gmail.com \\ "Corresponding author: Department of Traditional Persian Medicine, School of Medicine, Shiraz University of Medical Sciences, Shiraz, Iran. Tel: +98-9177032019, Email: \\ mnimruzi@yahoo.com
}

Received 2018 March 27; Revised 2018 August 16; Accepted 2018 August 20.

\begin{abstract}
Background: Personality and personality disorders are important in psychology. In addition, mizaj is a key concept of Persian medicine, according to which, it can affect the personality of the staff of an organizations.

Objectives: The aim of this study was to find the relationship between personality types based on NEO-FFI questionnaire, and mizaj, based on the knowledge of Persian medicine.

Methods: This is a cross-sectional descriptive analytical study. The participants were selected from 20 - 40-year-old staff of the medical school of Shiraz University of Medical Sciences through 2016. Mojahadi's questionnaire, including 10 questions based on threepoint Likert scale for the assessment of the mizaj as well as the NEO-FFI questionnaire, which includes 60 questions based on fivepoint Likert scale for the assessment of personality type were used in this study. SPSS 18 was performed for analyzing the data.

Results: Overall, 112 staff members, including 20 men (17.9\%) and 92 women (82.1\%) enrolled in the study. The mean age of the participants was $32.29 \pm 5.10$ years. In this study, neuroticism was positively related with hot temperament $(P=0.02)$. However, there was no statistically significant relationship between other aspects of temperament and personality $(\mathrm{P}>0.05)$.

Conclusions: The correlation of hot temperament and neuroticism is in line with the concept of Persian medicine. However, more research is needed to reveal more aspects of the relationship between temperament and personality.
\end{abstract}

Keywords: Personality, Persian Medicine, Temperament

\section{Background}

Traditional medicine, as defined by WHO, comprises a spectrum of medical therapies and preventive measures consisting of herbal, non-herbal, and manual treatments (acupuncture, cupping, and massage), which is indigenous to an area such as Chinese medicine and Indian Ayurveda. However, traditional medicine may be considered as complementary, if it is used by people of other countries $(1,2)$. Mizaj or temperament is a notion that is considered a key concept among ancient physicians and sages of Persia and Greece and is commonly used in natural philosophy, medical treatises, and textbooks $(3,4)$.

According to Persian medicine (PM) sources, temperament is defined as an average quality produced by the interaction of quadruple elements (fire, air, water, and soil), which possess their own unique dual qualities $(5,6)$. Interaction of fire (hot-dry), air (hot-wet), water (cold-wet), and soil (cold-dry) gives rise a dual quality, which is the average of a homogenous quality addressed as temperament $(7,8)$.

Mizaj is simple, if a simple quality is predominant such as hotness, coldness, wetness, and dryness. If the active qualities of hotness and wetness are balanced, the outcome will be a simple wet temperament or a simple dry temperament, depending on the predominance of wetness or dryness. Given the balance of passive qualitieswetness and dryness-the result will be a simple hot temperament or simple cold temperament, depending on the predominance of hotness or coldness. Compound temperaments are produced when either active or passive qualities are imbalanced, which is a combination of predominantly active and predominantly passive qualities including hot- 
dry, hot-wet, cold-dry, and cold-wet $(9,10)$.

Average temperament is equal to health; however, the true average that is completely equal in qualities of hotness, coldness, wetness, and dryness does not really exist in the world. What is considered a healthy temperament is the assumed average quality in which the combination of the quadruple qualities in human kind regarding time, place, and age results in the best functionality, mentality, and physical attributes. Arbitrarily, from the combination of simple and compound temperaments, we have nine types of temperaments, one average and eight out of range $(7,8,10)$.

Determination of the temperament plays a crucial role in the diagnosis of health and diseases in the PM school (5, 7). There is a set of 10 questions, adjnaas-e-ashareh, to determine temperament in general including touch (perception of physician from patient's skin touch), appearance, physique, hair, sleep and wakefulness, quality of body organ functions, quality of body wastes, and body impression by quadruple qualities and mental states $(10,11)$. The estimate of the physician, based on these 10 variables, indicates the general temperament of the examined person. According to the PM approach, people with different temperaments possess different mental characteristics (12).

There are a variety of interpretations regarding the concept of temperament in the conventional approach comprising blood acidity, thyroid hormone levels, homeostasis, acid base equilibrium, neuroendocrine hormones, and other biomarkers (3).

Personality, etymologically, is defined as a mask that actors used in ancient Greek theater to cover their face. The main concept of personality is usually tailored according to the social-end formal image of a person in the community (13). Different definitions for personality are rooted in different views. Personality is considered as one of the contributing factors forming individual behavior and different personal characteristics. Personality, usually consolidated and unchangeable, describes behaviors that individuals show while dealing with different situations. There are various models to determine and evaluate personality. One of these models, NEO-FFI, has been used in different studies. Several studies, with five-factor models, have been done to determine the relationships between the personality of people of different communities, taking into account learning, social deprivation, and other crucial factors (1315).

According to our literature review, there was no study evaluating the relation between temperament and personality, two important determinants of personal characteristics in traditional and conventional approach, respectively. It is also very important to adapt an employee's temperament and personality characteristics to the tasks assigned to them in the office. For this reason, our study compares Mojahedi's temperament questionnaire (16) and NEO-FFI personality questionnaire in the population.

\section{Methods}

\subsection{Design of the Study}

It is a cross-sectional descriptive analytical research into the temperament of a normal population compared with their personality dimensions according to the fivefactor model. This study was performed in the medical school of the Shiraz University of Medical Sciences. The minimum sample size was calculated considering $\alpha=0.05$ and $\beta=0.20$, and a 0.3 correlation coefficient for the relationship between mizaj and the personalities of 112 individuals. However, due to the low number of staff at the medical school, it was decided that all eligible employees would be enrolled in the study.

\subsection{Participants}

Shiraz medical school staff, between the ages of 20 and 40 years, reporting generally good health status, were selected from the list of university human resources office. People with a history of chronic diseases and those uninterested in participating in the study were omitted from the list; about 112 individuals were included in the study through 2016.

\subsection{Method of Temperament Determination}

Mojahedi's questionnaire, the first valid and reliable instrument for measuring the temperament, was used to determine the temperament of the participants. The questionnaire was a three-point Likert scale, with responses ranging from 1 to 3 , including the first eight questions for evaluation of the hotness-coldness range and the last two for the determination of the wetness-dryness range (16). The questionnaire was filled and a PhD in PM evaluated the temperament of the patient.

\subsection{Personality questionnaire}

The personality of the participants was evaluated by the NEO-FFI standard questionnaire consisting of 60 valid questions. The model comprises of five factors including neuroticism, extraversion, openness, agreeableness, and conscientiousness (17). The Persian version of normalization was done by Amrai et al. and Garusi Farshi $(18,19)$. The participants received a NEO-FFI Persian version questionnaire and, after being explained the details of the method of responding to the questions, were asked to fill the questionnaires. At the end, an expert psychologist determined the personality type of the participant according to their answers. 


\subsection{Ethics}

Verbal informed consent was received from the participants and they were assured that all information gathered from them would be secured by researchers and would not be published.

\subsection{Statistical Analysis}

After collecting the information and scoring based on the questionnaire guidelines, the crude data was analyzed by a statistician with SPSS 18 . The relationship between temperament and personality was evaluated with proper statistical tests. Descriptive statistics were included in mean and standard deviation for quantitative parameters and frequency count and percentage for qualitative variables. In addition, Independent t-test, ANOVA, Chi-square, and Pearson and Spearman correlation coefficient were used for an analytical explanation of the results.

\section{Results}

A total of 112 individuals, including 20 men (17.9\%) and 92 women (82.1\%), participated in the study. The mean ages of men and women were $32.20 \pm 4.23$ and $32.32 \pm$ 5.29 , respectively, however, it was not statistically significant $(\mathrm{P}=0.92)$. Of the participants, $57.1 \%$ were married and $34.8 \%$ had master degrees or higher (Table 1). Regarding the warmness-coldness temperament, $55.4 \%$ were average, and based on dryness-wetness, about $34.4 \%$ and $39.3 \%$ were dry and average, respectively (Table 2). Most of the participants were in level-2 in all personality facets, encompassing the average range. Accordingly, no one was in the high level of personality and few people fell in the low level (Table 3). There is a relationship between different temperaments and various personality levels in a way that warm or hot-temperament is significantly related to neuroticism $(P=0.02)$, however, there is no statistically significant relation among other temperaments with individuals' personalities $(P>0.05)$ (Table 4). Regarding the wetness-dryness temperament, there is a statistically significant relation between wetness and extraversion $(\mathrm{P}=0.009)$ (Table 5).

\section{Discussion}

According to PM knowledge, hot-dry tempered people are probably more irascible and hot-blooded. They are usually impatient, acute, fast, and furious. They are active, ready-witted and rapid-analyzers. People with a dominance of hot-dry temperament may suffer insomnia and light sleep $(20,21)$. Hot-wet tempered individuals are usually brave, venturous, genial, and warm. General characteristics of cold-tempered people are sluggishness and

\begin{tabular}{|c|c|}
\hline Variables & Value \\
\hline Age, $y$ & $32.29 \pm 5.10$ \\
\hline Males age & $32.20 \pm 4.23$ \\
\hline Females age & $32.32 \pm 5.29$ \\
\hline \multicolumn{2}{|l|}{ Sex } \\
\hline Male & $20(17.9)$ \\
\hline Female & $92(82.1)$ \\
\hline \multicolumn{2}{|l|}{ Marital status } \\
\hline Single & $36(32.1)$ \\
\hline Married & $64(57.1)$ \\
\hline Widowed & $3(2.7)$ \\
\hline Missing data & $9(8)$ \\
\hline \multicolumn{2}{|l|}{ Level of education } \\
\hline Diploma and lower & $12(10.7)$ \\
\hline Associate's degree & $5(4.9)$ \\
\hline Bachelor's degree & $48(49.8)$ \\
\hline Master's degree and doctorate & $38(34.8)$ \\
\hline Weight, kg & $86.17 \pm 12.23$ \\
\hline Height, kg & $165.09 \pm 8.35$ \\
\hline BMI, $\mathrm{kg} / \mathrm{m}^{2}$ & $23.70 \pm 2.94$ \\
\hline \multicolumn{2}{|l|}{ BMI category } \\
\hline$<18.5$ & $1(0.9)$ \\
\hline $18.51-24.99$ & $57(50.9)$ \\
\hline $25.00-29.99$ & $25(22.3)$ \\
\hline$>30$ & $3(2.7)$ \\
\hline Missing & $26(23.2)$ \\
\hline
\end{tabular}

${ }^{\mathrm{a}}$ Values are expressed as mean $\pm \mathrm{SD}$ or No. (\%).

weariness in mental states. Other specific characteristics of these people are cautiousness, fear, taciturnity, and indecision at the time of talking. People with cold-dry temperament are very stable and usually work in peace without haste. They are usually astute, stringent, introverted, and cold in relationships and are susceptible to depression. Cold-wet tempered people are forgetful, drowsy, and cold. It is crucial to know that implications of temperament are not absolute in all conditions (10, 21, 22).

Jorjani, in Zakhireh-e-Kharazmashahi, described the characteristics of hot-tempered, cold-tempered, wettempered, and dry-tempered people in detail. In addition, he described the characteristics of people with compound temperament. According to Jorjani's views of the temperament of the brain, people possessing hot-dry and dry-tempered brains gain acuteness in their sensory 


\begin{tabular}{|c|c|}
\hline Mizaj & Value \\
\hline \multicolumn{2}{|l|}{ Hot or cold Mizaj } \\
\hline Hot & $35(31.3)$ \\
\hline Moderate & $65(55.4)$ \\
\hline Cold & $15(13.4)$ \\
\hline \multicolumn{2}{|l|}{ Dry or wet Mizaj } \\
\hline Dry & $43(38.4)$ \\
\hline Moderate & $44(39.3)$ \\
\hline Wet & $25(22.3)$ \\
\hline \multicolumn{2}{|c|}{ Mixed Mizaj of participant } \\
\hline Hot and dry & $14(12.5)$ \\
\hline Hot and wet & $8(7.1)$ \\
\hline Cold and dry & $5(4.5)$ \\
\hline Cold and wet & $3(2.7)$ \\
\hline Moderate & $24(21.4)$ \\
\hline Hot & $12(10.7)$ \\
\hline Cold & $7(6.3)$ \\
\hline Wet & $14(12.5)$ \\
\hline Dry & $25(22.3)$ \\
\hline
\end{tabular}

perception. It means that they react more rapidly and more vigorously to external stimuli. They are usually quick-witted and, concurrently, irascible individuals. People with wet and cold-wet temperament brains, on the contrary, react slowly to stimuli and are usually more tolerant and, concurrently, slower in sensory perception $(21,23)$.

Amrai et al. found a positive relation between spiritual intelligence and conscientiousness, agreeableness, and extroversion. They also showed a negative relation between neuroticism and spiritual intelligence (18).

According to a study by Salary and Shaieri there is a positive relation between happiness and extraversion. In addition, a negative relationship between happiness and suffering was revealed in this study. However, no significant relationship was seen between happiness and personality psychosis (24). Our study showed that most people with extraversion were in the moderate and hot temperament groups, however, only a small part were in the group with cold temperament (Table 4). It is in accordance with the results of Salary's study and also in line with PM sources that cold-tempered people are usually low-energy and introvert (10).

Mottus et al. found a relation between openness and dietary style in elderly people (25). The elderly usually pos- sess cold temperament, according to PM, and, regarding wetness-dryness, their main organs such as CNS tend to be dry, however, their GI tends to have an accumulation of foreign moistness (26). In a study by Safarzadeh et al. the maximum sense of responsibility was found in cold-dry temperament, the least extraversion in cold-wet temperament, and the most gained experience in hot-dry temperament individuals. They also found that people with coldwet temperament possessed the maximum emotional stability, while people with hot-wet temperament liked the rule in comparison to the others. This study showed a relation between choleric (hot-dry) temperament and openness (27), however, it was not in line with the results of our study that showed more frequent open personality traits in people who were average in hotness-coldness (Table 4).

Inconsistent results in different studies regarding the relation between personality and temperament (mizaj) may be due to different tools measuring mizaj and in the observance of the body organs' mizaj per se. To correct this fault and obtain more precise results, researchers in the field of PM should design standard tools for measuring mizaj of each body organ separately, with the whole body representing the average mizaj of all body organs.

\subsection{Limitations}

We distinguish that one of the limitations of our study may be low sample size; therefore, to confirm the results, a future study with a larger sample size is recommended. The other is a higher number of women comparing to men, which was due to a high female to male ratio among the staffs of Shiraz Medical School.

\subsection{Conclusion}

Some temperament variables correlated with the fivefactor personality questionnaire, which was a promising step in tailoring comparative studies and enlisting PMneglected capacities in field of psychoanalysis. PM suggests some lifestyle health measures including dietary changes for individuals with different temperaments. Based on the results of this study, hot and wet temperaments are correlated with neuroticism and extraversion, respectively. Taking advantage of PM nutritional measures to correct deviated temperament or suggest some dietary and herbal remedies to balance temperament may alleviate some negative personality traits. It may be a good target for researchers to design vigorous clinical trials for the evaluation of recommended foods and drinks in different individuals with different temperaments in the context of personality disorders. 


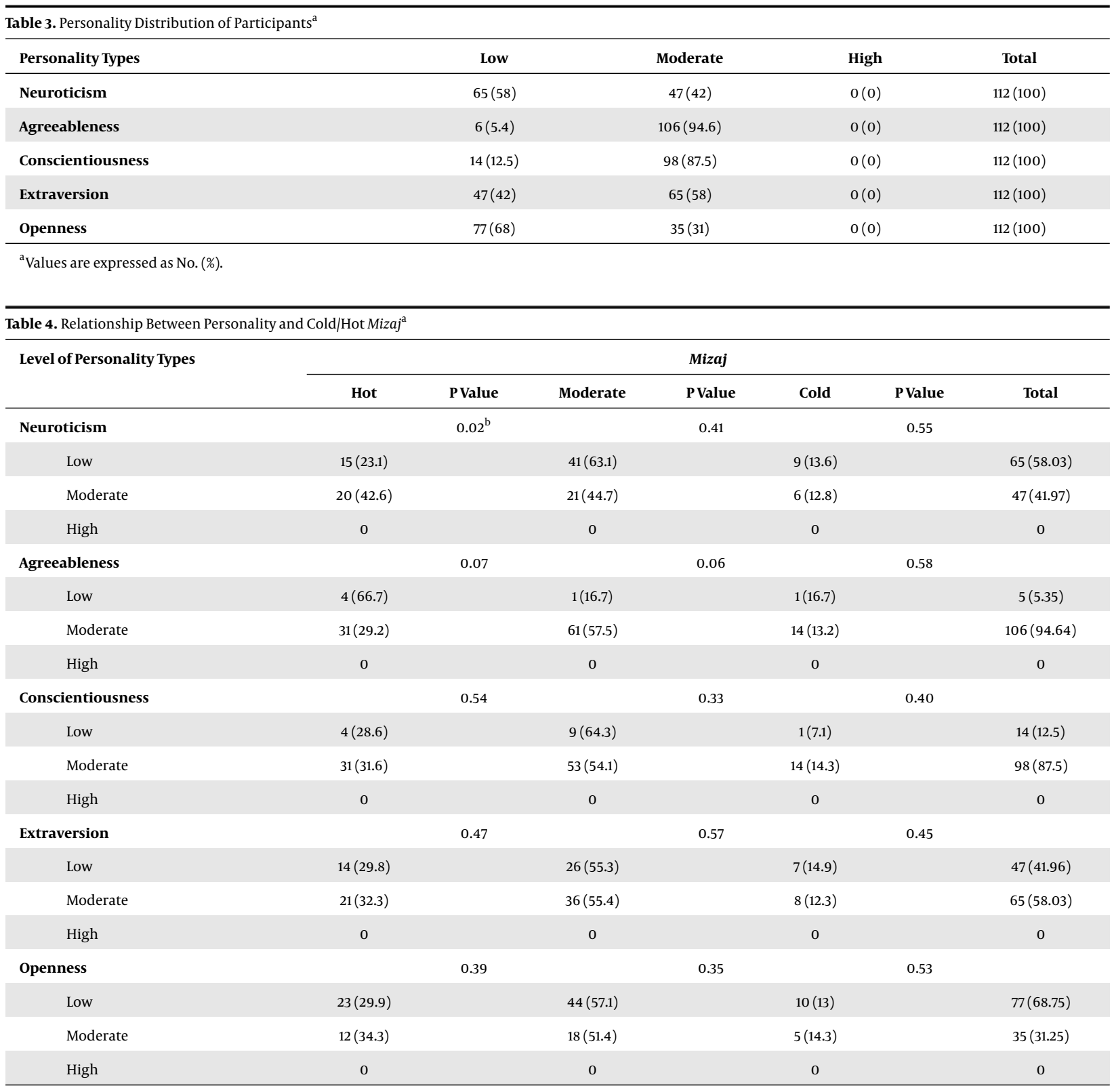

${ }^{\mathrm{a}}$ Values are expressed as No. (\%).

${ }^{\mathrm{b}}$ Statistically significant.

\section{Acknowledgments}

This study was supported by the vice chancellery of research, Research Center for Traditional Medicine and History of Medicine, Shiraz University of Medical Sciences, Shiraz, Iran (Grant No. 10541). The authors would like to thank the managers and staff of the medical school of Shiraz University of Medical Sciences, Shiraz, for their invaluable assistance.

\section{Footnotes}

Authors' Contribution: Study concept and design, Mohammad Mahdi Parvizi, Majid Nimrouzi, Alireza Salehi; acquisition of data, Mohammad Mahdi Parvizi, Majid Nimrouzi, Fatemeh Amini, Mahdie Hajimonfarednejad, Reza Mousavi Shirazi; statistical analyses, Mohammad Mahdi Parvizi, Pyruz Rezaie; drafting of the manuscript, Mohammad Mahdi Parvizi, Majid Nimrouzi, Mehdi Pasalar; critical revision of the manuscript for important intellectual con- 


\begin{tabular}{|c|c|c|c|c|c|c|c|}
\hline \multirow[t]{2}{*}{ Level of Personality Types } & \multicolumn{7}{|c|}{ Mizaj } \\
\hline & Wet & PValue & Moderate & PValue & Dry & PValue & Total \\
\hline Neuroticism & & 0.32 & & 0.35 & & 0.57 & \\
\hline Low & $13(20)$ & & $27(41.5)$ & & $25(38.5)$ & & $65(58.03)$ \\
\hline Moderate & $12(25.5)$ & & $17(36.2)$ & & $18(38.3)$ & & $47(41.96)$ \\
\hline High & 0 & & 0 & & 0 & & 0 \\
\hline Agreeableness & & 0.21 & & 0.55 & & 0.15 & \\
\hline Low & $0(0)$ & & $2(33.3)$ & & $4(66.7)$ & & $6(5.35)$ \\
\hline Moderate & $25(23.6)$ & & $42(39.6)$ & & $39(36.8)$ & & $106(94.64)$ \\
\hline High & 0 & & 0 & & 0 & & 0 \\
\hline Conscientiousness & & 0.35 & & 0.49 & & 0.46 & \\
\hline Low & $2(14.3)$ & & $6(42.9)$ & & $6(42.9)$ & & $14(12.5)$ \\
\hline Moderate & $23(23.5)$ & & $38(38.8)$ & & $37(37.8)$ & & $98(87.5)$ \\
\hline High & 0 & & 0 & & 0 & & 0 \\
\hline Extraversion & & $0.009^{\mathrm{b}}$ & & 0.11 & & 0.28 & \\
\hline Low & $5(10.6)$ & & $22(46.8)$ & & $20(42.6)$ & & $47(41.96)$ \\
\hline Moderate & $20(30.8)$ & & $22(33.8)$ & & $23(35.4)$ & & $65(58.03)$ \\
\hline High & 0 & & 0 & & 0 & & 0 \\
\hline Openness & & 0.12 & & 0.23 & & 0.48 & \\
\hline Low & $20(26)$ & & $28(36.4)$ & & $29(37.7)$ & & $77(68.75)$ \\
\hline Moderate & $5(14.3)$ & & $16(45.7)$ & & $14(40)$ & & $35(31.25)$ \\
\hline High & 0 & & 0 & & 0 & & 0 \\
\hline
\end{tabular}

${ }^{\mathrm{a}}$ Values are expressed as No. (\%).

${ }^{\mathrm{b}}$ Statistically significant.

tent: Majid Nimrouzi, Mehdi Pasalar, Mohammad Mahdi Parvizi; study supervision, Majid Nimrouzi, Mehdi Pasalar, Alireza Salehi.

Funding/Support: This study was financially supported by the Vice Chancellery of Research, Shiraz University of Medical Sciences, Shiraz, Iran (Grant No. 10541).

Ethical Considerations: Verbal informed consent was received from the participants and they were assured that all information gathered from them would be secured by researchers and would not be published.

\section{References}

1. World Health Organization. WHO traditional medicine strategy 20022005. 2002.

2. Pietroni PC. Beyond the boundaries: Relationship between general practice and complementary medicine. BMJ. 1992;305(6853):564-6. doi: 10.1136/bmj.305.6853.564. [PubMed: 1393039]. [PubMed Central: PMC1883275].

3. Ahanchimark O, Saiedimehr M. Reviewing the concept of temperament on the basis of modern medicine. Philosophy Sci. 2011;1(2):1-23.
4. Jabin F. A guiding tool in Unani Tibb for maintenance and preservation of health: A review study. Afr J Tradit Complement Altern Med. 2011;8(5 Suppl):140-3. doi: 10.4314/ajtcam.v8i5S.7. [PubMed: 22754067]. [PubMed Central: PMC3252723].

5. Akbari MA. [Mofareh Al-Gholub]. Tehran: Al-Maaye; 1915. Persian.

6. Nimrouzi M, Borzoo S, Salehi A. [Management of anorexia from the viewpoint of Arzani in Mizan-al-Teb]. J Islamic Iran Med. 2015;6(1):4362. Persian.

7. Nimrouzi M, Salehi A, Ahmadi A, Kiani H. Avicenna's medical didactic poem: Urjuzehtebbi. Acta Med Hist Adriat. 2015;13 Suppl 2:45-56. [PubMed: 26959631].

8. Naseri M. [Review of Iranian traditional medicine basics]. Tehran: Shahed University; 2008. p. 152-4. Persian.

9. Nimrouzi M, Zare M. Principles of nutrition in Islamic and traditional Persian medicine. J Evid Based Complementary Altern Med. 2014;19(4):267-70. doi: 10.1177/2156587214542006. [PubMed: 25027179].

10. Avicenna H. Ghanoon dar teb [the canon of medicine]. 9th ed. Tehran: Soroush Publication;1978. p. 413-7. Persian.

11. Nimrouzi M, Zarshenas MM. Functional constipation in children: Non-pharmacological approach. J Integr Med. 2015;13(2):69-71. doi: 10.1016/S2095-4964(15)60152-2. [PubMed: 25797636].

12. Nimrouzi M, Pasalar M. Role of dietary and lifestyle modifications in reflex epilepsy based on traditional Persian medicine. $J$ Integr Med. 2017;15(1):8-10. doi: 10.1016/S2095-4964(17)60309-1. [PubMed: 28088254]. 
13. Helle AC, Trull TJ, Widiger TA, Mullins-Sweatt SN. Utilizing interview and self-report assessment of the five-factor model to examine convergence with the alternative model for personality disorders. Personal Disord. 2017;8(3):247-54. doi: 10.1037/per0000174. [PubMed: 26986962].

14. Detrick $\mathrm{P}$, Chibnall JT. A five-factor model inventory for use in screening police officer applicants: The revised NEO personality inventory (NEO PI-R). Police psychology and its growing impact on modern law enforcement. IGI Global; 2017. p. 79-92.

15. Strober LB. Personality in multiple sclerosis (MS): Impact on health, psychological well-being, coping, and overall quality of life. Psychol Health Med. 2017;22(2):152-61. doi: 10.1080/13548506.2016.1164321. [PubMed: 26987417]. [PubMed Central: PMC5214537].

16. Mojahedi M, Naseri M, Majdzadeh R, Keshavarz M, Ebadini M, Nazem E, et al. Reliability and validity assessment of mizaj questionnaire: A novel self-report scale in Iranian traditional medicine. Iran Red Crescent Med J. 2014;16(3). e15924. doi: 10.5812/ircmj.15924. [PubMed: 24829785]. [PubMed Central: PMC4005447].

17. Egan V, Deary I, Austin E. The NEO-FFI: Emerging British norms and an item-level analysis suggest $\mathrm{N}, \mathrm{A}$ and $\mathrm{C}$ are more reliable than $\mathrm{O}$ and $\mathrm{E}$. Pers Individ Dif. 2000;29(5):907-20. doi: 10.1016/s0191-8869(99)002421.

18. Amrai K, Farahani A, Ebrahimi M, Bagherian V. Relationship between personality traits and spiritual intelligence among university students. Procedia Soc Behav Sci. 2011;15:609-12. doi: 10.1016/j.sbspro.2011.03.149.

19. Garusi Farshi M. [Normalizing personality scale NEOPI-R, analytical investigation of personality traits and its factor construction among Iranian university students]. Tehran: Tarbiat Modares University; 1998. Persian.
20. Feyzabadi Z, Jafari F, Feizabadi PS, Ashayeri H, Esfahani MM, Badiee Aval S. Insomnia in Iranian traditional medicine. Iran Red Crescent Med J. 2014;16(3). e15981. doi: 10.5812/ircmj.15981. [PubMed: 24829786]. [PubMed Central: PMC4005448].

21. Jorjani E. [Zakhire kharazmshahi]. Tehran: Iranian Medical Academy; 2001. Persian.

22. Fattahi MR, Alorizi SME, Nimrouzi M, Zarshenas MM, Parvizi MM. A randomized clinical trial on treatment of chronic constipation by traditional Persian medicine recommendations compared to allopathic medicine: A pilot study. Int J Prev Med. 2017;8:50. doi: 10.4103/ijpvm.IJPVM_302_16. [PubMed: 28757927]. [PubMed Central: PMC5516435].

23. Parvizi MM, Nimrouzi M, Bagheri Lankarani K, Emami Alorizi SM, Hajimonfarednejad $M$. Health recommendations for the elderly in the viewpoint of traditional Persian medicine. Shiraz E-Med J. 2018;19(1). doi: $10.5812 /$ semj.14201.

24. Salary S, Shaieri MR. Study of the relationship between happiness and dimensions of psychosis, neurosis and personality extraversion. Procedia Soc Behav Sci. 2013;84:1143-8. doi:10.1016/j.sbspro.2013.06.716.

25. Mottus R, McNeill G, Jia X, Craig LC, Starr JM, Deary IJ. The associations between personality, diet and body mass index in older people. Health Psychol.2013;32(4):353-60. doi:10.1037/a0025537. [PubMed: 21928903].

26. Nimrouzi M, Zarshenas MM. Management of anorexia in elderly as remarked by medieval Persian physicians. Acta Med Hist Adriat. 2015;13 Suppl 2:115-28. [PubMed: 26959636].

27. Safarzadeh H, Soloukdar A, Rezaeizadeh H. Studying the effects of organizational personality traits on different human temperaments based on the five-factor model of personality. Caspian J Appl Sci Res. 2013;2(3). 